\title{
Produktivitas rumput gajah (Pennisetum purpureum cv Taiwan) hasil irradiasi sinar gamma pada dosis 50 Gy
}

\section{Productivity of elephant grass (Pennisetum purpureum cv Taiwan) from gamma ray irradiation at a dose of $50 \mathrm{~Gy}$}

\author{
Harmini Harmini ${ }^{*}$, Sajimin Sajimin ${ }^{1}$, Achmad Fanindi ${ }^{1}$, Ali Husni ${ }^{2}$ \\ ${ }^{1}$ Balai Penelitian Ternak, Jl. Veteran III Banjar Sari, Ciawi, Bogor, 16720, Jawa Barat, Indonesia \\ ${ }^{2}$ Balai Besar Penelitian Bioteknologi dan Sumberdaya Genetik. Jl.Tentara Pelajar 3A Cimanggu, Bogor 16124, Jawa Barat, \\ Indonesia \\ *Email Koresponden: hmini2011@gmail.com
}

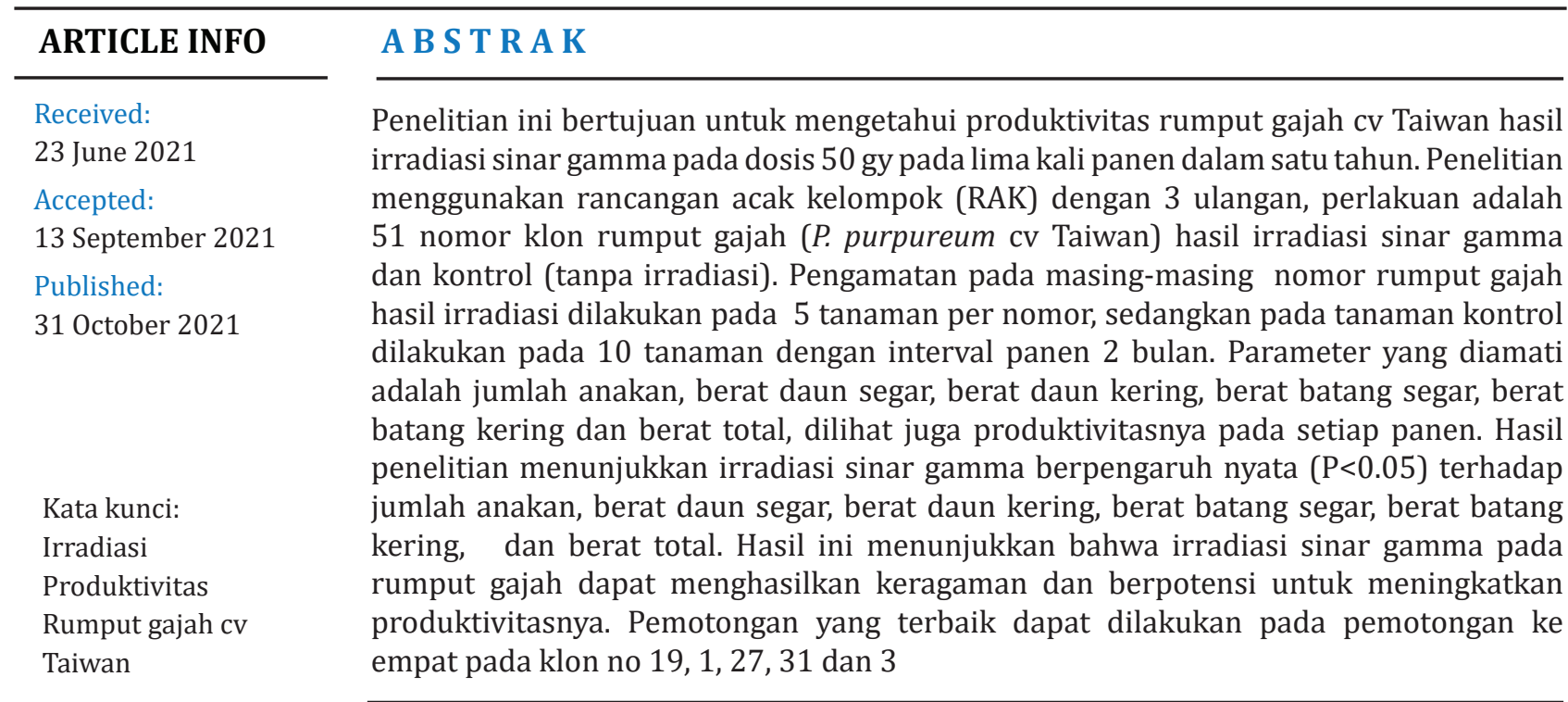

\section{A B S T R A C T}

The study aims to determine the productivity of elephant grass cv Taiwan (Pennisetum purpureum cv Taiwan) from gamma ray irradiation at a dose of 50 gy at five harvest in one year. The study used a randomized block design (RBD) with 3 replications, the treatment was 51 numbers clone of elephant grass ( $P$. purpureum cV Taiwan) from gamma ray irradiation and control (without irradiation). Observations were made on each number of elephant grass irradiated on 5 plants per number, and were made on 10 plantswith a harvest interval of 2 months. The observed parameters include the number of tillers; fresh and dry leaf weight; fresh and dry stem weight, and total weight. The results showed a

Key words: significant impact of gamma radiation $(P<0.05)$ on tiller count, fresh leaf weight, dry leaf

Irradiation,

Productivity

Napier grass $\mathrm{CV}$

Taiwan weight and fresh stem weight as well as dry stem weight and total weight. These results show that gamma radiation on elephant grass can generate diversity and increase its productivity. The best cuttings can be made on the fourth cut in clones no. 19, 1, 27, 31 and 3.

\section{PENDAHULUAN}

Rumput gajah cv Taiwan berdasarkan kandungan proteinnya tergolong rumput dengan kualitas tinggi, namun berdasar kandungan Neutral Detergent Fiber (NDF) dan Acid Detergent Fiber (ADF) tergolong kualitas medium, peningkatan interval defoliasi meningkatkan karakteristik pertumbuhan, tetapi menurunkan kualitas nutrisinya, sedangkan 
pemberian pupuk organik cair meningkatkan karakteristik pertumbuhan dan kandungan bahan kering tetapi tidak berpengaruh tehadap kualitasnya (Lestari et al., 2018). Produksi bahan kering tertinggi pada rumput gajah cv Taiwan pada umur panen 13 minggu dan kualitas tertinggi pada umur panen 8 minggu (Budiman et al., 2012). Pada umur panen 35 hari produksi bahan kering rumput gajah cv Taiwan 3,43 ton ha-1 panen-1 dengan kandungan BK, PK, SK dan energi berturut - turut 10,$67 ; 17,23 ; 32,23$ dan 8,83\% (Haryani et al., 2018).

Pemuliaan tanaman secara konvensional (banyak atau dalam jumlah besar) dilakukan dengan hibridisasi (perkawinan silang berbagai jenis spesies setiap tanaman), sedangkan pemuliaan secara mutasi dapat diinduksi dengan mutagen fisik atau mutagen kimia. Sinar gamma adalah radiasi elektromagnetik yang dihasilkan oleh radioaktivitas yang membentuk spectrum elektromagnetik energy tertinggi, yang dapat menekan pertumbuhan akar, batang, dan daun (pertumbuhan vegetatif). Dosis radiasi yang diberikan untuk mendapatkan individu yang memperlihatkan perubahan sifat (mutan) tergantung pada jenis tanaman, fase tumbuh, ukuran, kekerasan, dan bahan yang akan dimutasi.

Pemanfaatan radiasi sinar gamma pada berbagai konsentrasi diharapkan mendapatkan jenis varietas unggul yang mempunyai karakter buah yang baik dari sebelumnya. Dosis radiasi yang diberikan untuk mendapatkan individu yang memperlihatkan perubahan sifat (mutan) tergantung pada jenis tanaman, fase tumbuh, ukuran, kekerasan, dan bahan yang akan dimutasi. Pemanfaatan radiasi sinar gamma pada berbagai konsentrasi diharapkan mendapatkan jenis varietas unggul yang mempunyai karakter buah yang baik dari sebelumnya. Radiasi gamma dengan dosis yang terlalu tinggi diatas $700 \mathrm{~Gy}$, sedangkan untuk dosis rendah 200 sampai 300 Gy untuk biji, namun untuk plantlet lebih rendah. Dosis yang terlalu tinggi dapat memberikan efek negatif langsung pada tanaman, karena dapat menyebabkan tanaman mati.

Metode pemuliaan dengan teknik iradiasi sinar gamma telah banyak dilakukan pada tanaman pangan, tanaman perkebunan, namun masih sedikit pada tanaman pakan. Pada kedelai hitam ((Glycine max (L.) Merrill) radiasi berpengaruh tarhadap tinggi tanaman, umur berbunga, umur panen, jumlah polong hampa, bobot biji per sampel, dan bobot 100 biji (Purba et al., 2013). Seleksi dengan irradiasi sinar gamma pada tanaman pakan ternak (TPT) selain untuk menghasilkan TPT produksi tinggi juga untuk TPT pada lahan sub optimal atau cuaca ekstrim (Harmini et al., 2020). Penelitian ini bertujuan untuk mencari TPT dengan regrowth yang cepat serta rasio daun dan batang yang tinggi, serta produksi bahan kering yang tinggi.

\section{MATERI DAN METODE}

\section{Bahan Penelitian menggunakan klon} mutan rumput gajah (RG) (Pennisetum purpureum cv Taiwan) sebanyak 51 nomor hasil irradiasi sinar gamma 50 GY dari planlet di Pusat Aplikasi Isotop dan Radiasi Badan Tenaga Atom Nasional (PAIR BATAN). Penelitian ini telah dilaksanakan di Kebun Percobaan Agrostologi, Balai Penelitian Ternak, yang berada pada ketinggian tempat $500 \mathrm{mdpl}$, dimulai pada Juni 2018 sampai Juli 2019

\section{Metode}

Percobaan dilakukan pada ukuran petak $1 \mathrm{~m} \times 2 \mathrm{~m}$ dengan jarak tanam $50 \mathrm{~cm}$. Rancangan penelitian menggunakan rancangan acak kelompok. Perlakuan adalah 51 nomor galur $P$. purpureum cv Taiwan hasil irradiasi sinar gamma ditambah satu nomor (no. 52) tanpa irradiasi sinar gamma sebagai kontrol, setiap perlakuan diulang 3 kali. Pengelompokan berdasarkan kondisi lahan. Pengamatan setelah tanaman dilakukan pemerataan (umur 3 bulan) dan pemotongan berikutnya setiap 2 bulan (interval potong)

\section{Peubah yang diamati}

Peubah yang diamati karakter agronomi meliputi, jumlah anakan. Pengamatan terhadap peubah produksi meliputi: berat total, berat daun (berat segar), berat daun (berat kering), berat batang (berat segar) dan berat batang (berat kering)

\section{Analisa Data}

Data dianalisis menggunakan sidik ragam, jika terdapat perbedaan yang nyata dilanjutkan dengan uji Duncan 


\section{HASIL DAN PEMBAHASAN}

Rata - rata per panen jumlah anakan, berat daun segar, dan berat daun kering dapat dilihat pada Tabel 1. Pada Tabel 1 menyatakan bahwa irradiasi sinar gamma berpengaruh nyata $(\mathrm{P}<0,05)$ terhadap rata - rata per panen untuk jumlah anakan, berat daun segar dan berat daun kering. Lima nomor dengan rata - rata jumlah anakan tertinggi adalah no. 19, 1, 27, 13 dan 28. Pada berat daun segar rata - rata tertinggi adalah no 52, 1, 19, 28 dan 38, sedangkan rata - rata berat daun kering tertinggi adalah no. 52, 49, 28, 45 dan 19. Rata - rata jumlah anakan per panen 13 sampai 40,6 per $2 \mathrm{M}^{2}$, sedangkan pada kontrol 29,6 per $2 M^{2}$.

Keragaman pada penelitian ini masih cukup tinggi jika dilihat dari range nilai terendah sampai tertinggi pada pengamatan di Tabel 1 , karena masih pada generasi M3. Rata - rata berat daun segar per panen pada penelitian ini 291,6 sampai 1011,2 gram per $2 \mathrm{M}^{2}$, hasil ini lebih rendah dibanding kontrol yang mencapai 2477 gram per $2 \mathrm{M}^{2}$. Berat daun kering per panen mempunyai rata - rata 56,8 sampai 196,6 gram per $2 \mathrm{M}^{2}$, lebih rendah dibanding kontrol yang mencapai 362,6 per $2 \mathrm{M}^{2}$. Dosis iradiasi sinar gamma berdampak pada kelainan morfologi tanaman seperti ukuran diameter batang dan daun menjadi kecil, serta daun kuning kehijauan (Astuti, 2007). Irradiasi sinar gamma biasanya akan berpengaruh terhadap karakter - karakter kuantitatif pada tanaman seperti tinggi tanaman, lebar daun, dan panjang daun. Hal ini akan berakibat pada produktivitas tanaman yaitu rata - rata berat segar dan berat kering pada daun. Mutasi merupakan suatu proses perubahan pada materi genetik dari suatu sel, yang mencakup perubahan pada tingkat gen, molekuler atau kromosom (Poehlman \& Sleper, 1995).

Irradiasi pada Panicum maximum pada dosis sampai 350 Gy menghasilkan jumlah anakan lebih besar dibanding kontrol (Fanindi et al., 2019). Hal ini sejalan pada Alfalfa dimana dosis irradiasi pada 300 Gy menghasilkan jumlah anakan terbanyak (Prihantoro et al., 2019). Pada

Tabel 1. Rata - rata jumlah anakan, berat daun segar dan berat daun kering per panen dalam setahun (lima kali panen) pada Rumput gajah cv Taiwan hasil irradiasi sinar gamma

\begin{tabular}{|c|c|c|c|}
\hline No & Jumlah anakan & Berat daun segar (gram) & Berat daun kering (gram) \\
\hline 1 & $38,80 \pm 10,39 a b$ & $1076,84 \pm 432,41 b$ & $169,73 \pm 84,35$ \\
\hline 2 & $27,90 \pm 14,73$ & $528,96 \pm 208,41$ & $148,87 \pm 83,19$ \\
\hline 3 & $27,72 \pm 8,79$ & $659,68 \pm 286,71$ & $122,00 \pm 15,98$ \\
\hline 4 & $13,70 \pm 5,16$ & $503,36 \pm 211,27$ & $83,93 \pm 43,48$ \\
\hline 5 & $28,98 \pm 8,17$ & $605,08 \pm 180,36$ & $150,10 \pm 76,46$ \\
\hline 6 & $22,15 \pm 8,03$ & $463,87 \pm 178,47$ & $165,60 \pm 154,50$ \\
\hline 7 & $20,94 \pm 7,16$ & $591,41 \pm 224,49$ & $95,03 \pm 16,91$ \\
\hline 8 & $29,59 \pm 8,97$ & $624,62 \pm 257,66$ & $113,27 \pm 40,77$ \\
\hline 9 & $22,96 \pm 5,85$ & $555,02 \pm 186,60$ & $110,81 \pm 84,51$ \\
\hline 10 & $31,03 \pm 10,89$ & $831,25 \pm 270,74$ & $133,07 \pm 47,89$ \\
\hline 11 & $30,56 \pm 9,57$ & $718,14 \pm 163,43$ & $122,77 \pm 63,74$ \\
\hline 12 & $18,12 \pm 7,73$ & $376,08 \pm 139,59$ & $56,77 \pm 3,07$ \\
\hline 13 & $32,44 \pm 8,96$ & $647,53 \pm 258,19$ & $99,30 \pm 40,51$ \\
\hline 14 & $25,26 \pm 9,22$ & $594,69 \pm 237,32$ & $157,00 \pm 121,38$ \\
\hline 15 & $30,64 \pm 9,99$ & $543,66 \pm 220,22$ & $95,40 \pm 32,72$ \\
\hline 16 & $24,11 \pm 8,20$ & $533,13 \pm 190,18$ & $92,07 \pm 47,81$ \\
\hline 17 & $27,60 \pm 8,96$ & $615,22 \pm 236,48$ & $99,17 \pm 54,96$ \\
\hline 18 & $26,12 \pm 9,32$ & $513,53 \pm 108,12$ & $89,17 \pm 49,80$ \\
\hline 19 & $40,45 \pm 12,20 a$ & $1011,35 \pm 412,19 b c$ & $170,73 \pm 65,79$ \\
\hline 20 & $28,57 \pm 9,18$ & $695,93 \pm 218,84$ & $102,90 \pm 53,63$ \\
\hline
\end{tabular}




\begin{tabular}{|c|c|c|c|}
\hline 21 & $26,24 \pm 9,37$ & $598,43 \pm 246,78$ & $118,70 \pm 63,98$ \\
\hline 22 & $18,88 \pm 7,15$ & $346,45 \pm 201,64$ & $85,17 \pm 70,12$ \\
\hline 23 & $27,11 \pm 9,37$ & $753,12 \pm 307,63$ & $128,30 \pm 41,54$ \\
\hline 24 & $20,83 \pm 8,28$ & $516,36 \pm 151,36$ & $84,90 \pm 40,86$ \\
\hline 25 & $27,24 \pm 9,10$ & $669,57 \pm 261,86$ & $109,47 \pm 25,50$ \\
\hline 26 & $13,10 \pm 5,51$ & $291,48 \pm 88,01$ & $63,87 \pm 32,37$ \\
\hline 27 & $33,48 \pm 10,10 \mathrm{abc}$ & $789,73 \pm 376,62$ & $108,27 \pm 20,29$ \\
\hline 28 & $31,34 \pm 8,73$ & $1008,92 \pm 446,17 \mathrm{bc}$ & $176,67 \pm 104,11 \mathrm{bc}$ \\
\hline 29 & $22,23 \pm 7,57$ & $426,01 \pm 172,07$ & $105,07 \pm 87,63$ \\
\hline 30 & $26,81 \pm 8,45$ & $768,88 \pm 342,04$ & $124,23 \pm 70,80$ \\
\hline 31 & $28,97 \pm 9,35$ & $775,38 \pm 316,10$ & $124,23 \pm 58,72$ \\
\hline 32 & $20,29 \pm 6,88$ & $431,27 \pm 133,29$ & $96,30 \pm 55,38$ \\
\hline 33 & $18,48 \pm 5,60$ & $507,48 \pm 254,34$ & $64,89 \pm 34,37$ \\
\hline 34 & $25,53 \pm 11,12$ & $619,26 \pm 315,35$ & $91,90 \pm 39,32$ \\
\hline 35 & $27,25 \pm 6,70$ & $673,06 \pm 201,45$ & $155,67 \pm 75,85$ \\
\hline 36 & $15,62 \pm 4,13$ & $455,63 \pm 153,41$ & $91,03 \pm 37,11$ \\
\hline 37 & $19,72 \pm 10,71$ & $395,79 \pm 171,04$ & $90,30 \pm 42,94$ \\
\hline 38 & $26,95 \pm 9,46$ & $865,77 \pm 387,91$ & $140,10 \pm 90,32$ \\
\hline 39 & $23,29 \pm 7,95$ & $563,86 \pm 288,08$ & $142,30 \pm 66,66$ \\
\hline 40 & $26,30 \pm 8,07$ & $792,97 \pm 368,74$ & $156,57 \pm 131,46$ \\
\hline 41 & $16,28 \pm 4,13$ & $436,80 \pm 151,91$ & $86,67 \pm 45,14$ \\
\hline 42 & $30,80 \pm 11,50$ & $541,94 \pm 194,39$ & $138,29 \pm 57,97$ \\
\hline 43 & $19,38 \pm 5,65$ & $492,92 \pm 143,54$ & $84,47 \pm 38,52$ \\
\hline 44 & $25,41 \pm 10,19$ & $632,91 \pm 304,64$ & $142,97 \pm 67,03$ \\
\hline 45 & $29,86 \pm 9,36$ & $699,46 \pm 324,93$ & $175,33 \pm 118,68 \mathrm{bc}$ \\
\hline 46 & $22,60 \pm 10,68$ & $474,79 \pm 175,67$ & $136,77 \pm 94,28$ \\
\hline 47 & $17,60 \pm 5,14$ & $477,16 \pm 231,03$ & $70,93 \pm 28,83$ \\
\hline 48 & $27,29 \pm 12,28$ & $657,51 \pm 242,50$ & $146,10 \pm 67,49$ \\
\hline 49 & $27,47 \pm 7,99$ & $789,77 \pm 204,32$ & $196,41 \pm 179,62 b$ \\
\hline 50 & $22,76 \pm 5,96$ & $770,95 \pm 329,77$ & $144,30 \pm 77,49$ \\
\hline 51 & $26,34 \pm 10,43$ & $701,87 \pm 314,03$ & $140,25 \pm 54,83$ \\
\hline kontrol & $29,72 \pm 8,47$ & $2477,10 \pm 595,48 \mathrm{a}$ & $362,40 \pm 206,92 a$ \\
\hline
\end{tabular}

Keterangan: $a, b, c=$ superskrip yang berbeda pada kolom yang sama menunjukkan yang nyata $(\mathrm{P} \leq 0,05)$

rumput benggala heritabilitas sedang sampai tinggi dengan nilai koefisien keragaman genetik (KKG) cukup tinggi sampai tinggi diperoleh pada karakter jumlah anakan, bobot segar dan bobot kering (Fanindi et al., 2016).

Rata - rata berat total, berat batang segar dan berat batang kering per panen dapat dilihat pada Tabel 2. Perlakuan irradiasi sinar gamma berpengaruh nyata $(\mathrm{P}<0.05)$ terhadap berat total (berat segar), berat batang segar dan berat batang kering. Lima nomer dengan rata - rata berat total (berat segar) tertinggi per panen adalah no. control, 1, 19, 27 dan 49; berat batang (berat segar) per panen rata - rata tertinggi 52, 19, 1, 49 dan 40 ; berat batang (berat kering) per panen rata - rata tertinggi 19, 1, 2, 10 dan 28. Rata - rata berat total per panen (berat segar ) 769,6 sampai 2760,6 gram, lebih rendah dibanding kontrol 6327,6 gram per $2 \mathrm{M}^{2}$, berat batang (berat segar) per panen dari 369,8 sampai 1435,6 gram per $2 \mathrm{M}^{2}$, lebih rendah dibanding kontrol mencapai 3618,4 gram per 2 
Tabel 2. Rata - rata berat total (berat segar), berat batang (berat segar) dan berat batang (berat kering) per panen

\begin{tabular}{|c|c|c|c|}
\hline No & Berat total (berat segar)(gram) & Berat batang segar (gram) & Berat batang kering (gram) \\
\hline 1 & $2760,29 \pm 1302,66 b$ & $1035,22 \pm 501,57 b c$ & $262,83 \pm 133,21 \mathrm{ab}$ \\
\hline 2 & $1253,43 \pm 583,31$ & $548,84 \pm 265,78$ & $247,23 \pm 250,90 \mathrm{abc}$ \\
\hline 3 & $2011,66 \pm 957,89$ & $721,64 \pm 358,82$ & $137,87 \pm 103,88$ \\
\hline 4 & $1206,11 \pm 553,30$ & $525,44 \pm 284,51$ & $117,27 \pm 63,29$ \\
\hline 5 & $1778,90 \pm 932,69$ & $642,43 \pm 282,59$ & $164,37 \pm 74,80$ \\
\hline 6 & $1318,13 \pm 593,34$ & $498,09 \pm 257,57$ & $112,87 \pm 54,63$ \\
\hline 7 & $1403,22 \pm 484,96$ & $594,75 \pm 269,45$ & $155,90 \pm 88,52$ \\
\hline 8 & $1826,44 \pm 880,36$ & $652,40 \pm 363,38$ & $152,53 \pm 68,78$ \\
\hline 9 & $1230,58 \pm 397,77$ & $537,07 \pm 216,50$ & $137,08 \pm 77,69$ \\
\hline 10 & $2220,76 \pm 1092,33$ & $841,43 \pm 370,93$ & $222,70 \pm 123,28$ \\
\hline 11 & $2028,45 \pm 1157,65$ & $763,64 \pm 233,90$ & $149,43 \pm 54,80$ \\
\hline 12 & $944,03 \pm 151,94$ & $369,83 \pm 139,41$ & $68,37 \pm 19,71$ \\
\hline 13 & $2004,30 \pm 1114,89$ & $609,67 \pm 275,52$ & $157,03 \pm 80,25$ \\
\hline 14 & $1176,72 \pm 494,39$ & $592,47 \pm 279,30$ & $136,57 \pm 67,58$ \\
\hline 15 & $1570,73 \pm 720,15$ & $541,88 \pm 298,15$ & $134,23 \pm 66,58$ \\
\hline 16 & $1835,13 \pm 1467,54$ & $501,90 \pm 228,19$ & $123,07 \pm 58,67$ \\
\hline 17 & $1881,91 \pm 1171,46$ & $570,33 \pm 261,18$ & $120,43 \pm 62,05$ \\
\hline 18 & $1084,26 \pm 445,43$ & $529,13 \pm 207,25$ & $108,87 \pm 40,16$ \\
\hline 19 & $2659,56 \pm 1163,55 b c$ & $1068,06 \pm 614,58 \mathrm{~b}$ & $269,00 \pm 126,25 a$ \\
\hline 20 & $1704,07 \pm 581,19$ & $769,43 \pm 351,44$ & $134,03 \pm 52,81$ \\
\hline 21 & $1670,83 \pm 837,46$ & $674,82 \pm 353,31$ & $170,10 \pm 87,57$ \\
\hline 22 & $782,20 \pm 379,67$ & $388,46 \pm 232,68$ & $109,67 \pm 63,26$ \\
\hline 23 & $2026,83 \pm 726,84$ & $808,25 \pm 410,88$ & $178,07 \pm 66,76$ \\
\hline 24 & $1652,58 \pm 852,34$ & $603,29 \pm 266,08$ & $109,27 \pm 45,75$ \\
\hline 25 & $1865,77 \pm 544,85$ & $747,86 \pm 419,54$ & $191,87 \pm 111,63$ \\
\hline 26 & $980,27 \pm 586,45$ & $320,79 \pm 125,62$ & $85,53 \pm 24,85$ \\
\hline 27 & $2445,03 \pm 1016,03$ & $780,23 \pm 433,30$ & $142,70 \pm 25,78$ \\
\hline 28 & $2035,00 \pm 1058,97$ & $917,04 \pm 520,68$ & $213,60 \pm 133,90$ \\
\hline 29 & $1098,67 \pm 608,42$ & $442,30 \pm 184,42$ & $114,40 \pm 86,27$ \\
\hline 30 & $1663,59 \pm 754,34$ & $699,29 \pm 349,51$ & $154,87 \pm 84,81$ \\
\hline 31 & $2029,09 \pm 1053,60$ & $751,08 \pm 390,51$ & $160,00 \pm 101,30$ \\
\hline 32 & $1239,64 \pm 650,13$ & $468,94 \pm 139,50$ & $116,00 \pm 57,94$ \\
\hline 33 & $1402,11 \pm 726,81$ & $499,77 \pm 356,01$ & $82,49 \pm 41,33$ \\
\hline 34 & $1698,56 \pm 697,99$ & $602,92 \pm 370,96$ & $121,17 \pm 55,55$ \\
\hline 35 & $1902,45 \pm 946,50$ & $674,58 \pm 299,01$ & $204,77 \pm 122,08$ \\
\hline 36 & $1211,07 \pm 602,54$ & $466,57 \pm 254,34$ & $104,63 \pm 36,79$ \\
\hline 37 & $1108,49 \pm 466,23$ & $462,74 \pm 251,43$ & $104,67 \pm 40,60$ \\
\hline 38 & $1645,94 \pm 1015,43$ & $770,57 \pm 484,79$ & $237,00 \pm 185,16$ \\
\hline 39 & $1159,53 \pm 632,12$ & $549,25 \pm 338,96$ & $160,33 \pm 89,67$ \\
\hline 40 & $2020,64 \pm 1171,59$ & $867,65 \pm 390,50$ & $169,58 \pm 142,70$ \\
\hline 41 & $769,56 \pm 364,53$ & $406,67 \pm 205,22$ & $88,97 \pm 49,39$ \\
\hline
\end{tabular}




\begin{tabular}{cccc}
42 & $1626,32 \pm 776,84$ & $650,17 \pm 207,66$ & $142,79 \pm 45,79$ \\
43 & $1313,08 \pm 664,84$ & $504,95 \pm 209,51$ & $98,87 \pm 39,21$ \\
44 & $1735,76 \pm 761,12$ & $641,51 \pm 408,04$ & $216,87 \pm 173,84$ \\
45 & $1809,33 \pm 937,53$ & $737,38 \pm 327,80$ & $203,13 \pm 128,24$ \\
46 & $1246,80 \pm 778,75$ & $405,91 \pm 201,63$ & $221,43 \pm 233,42$ \\
47 & $1101,78 \pm 515,08$ & $450,20 \pm 284,41$ & $80,57 \pm 35,20$ \\
48 & $2437,98 \pm 1315,49$ & $809,53 \pm 368,95$ & $180,93 \pm 78,20$ \\
49 & $2440,46 \pm 1343,85$ & $892,42 \pm 351,17 \mathrm{bcd}$ & $252,65 \pm 162,08$ \\
50 & $1704,75 \pm 915,33$ & $717,98 \pm 395,04$ & $201,90 \pm 111,78$ \\
51 & $1887,04 \pm 1229,89$ & $745,96 \pm 475,26$ & $201,73 \pm 101,13$ \\
kontrol & $6327,34 \pm 1236,76 \mathrm{a}$ & $3618,40 \pm 646,23 \mathrm{a}$ & $528,53 \pm 327,78$ \\
\hline
\end{tabular}

Keterangan: a,b,c,d = superskrip yang berbeda pada kolom yang sama menunjukkan yang nyata $(\mathrm{P} \leq 0,05)$

$\mathrm{M}^{2}$. Produktivitas hijauan yang menurun diduga karena irradiasi merusak kromosom tanaman sehingga produktivitas tanaman menurun. Semakin tinggi dosis irradiasi sinar gamma akan menurunkan pertumbuhan tunas, daun dan akar pada rumput gajah (Al Hafiizh \& Ermayanti, 2014). Karakteristik produksi tanaman dipengaruhi oleh factor genetiknya (Reddy et al., 2003).

Rata - rata produktivitas panen dapat dilihat pada Gambar 1. Berdasarkan waktu panen 1 dan 2 menghasilkan produktivitas tertinggi untuk berat daun segar, berat daun kering pada panen ke 3, pada berat batang (berat segar) pada panen ketiga, berat batang (berat kering) pada panen ketiga, dan berat total pada panen keempat. Disamping faktor genetik, produktivitas juga dipengaruhi oleh musim. Pada musim hujan produktivitas rumput gajah vc Taiwan meningkat karena mendapatkan curah hujan yang cukup. Pada musim kemarau akan mempercepat fase generative (berbunga), Cepatnya fase generative diduga karena pengaruh iradiasi sinar gamma (Gea et al., 2019). Kualitas tanaman akan menurun pada fase generative

\section{KESIMPULAN}

Hasil penelitian ini disimpulkan, bahwa irradiasi sinar gamma berpengaruh terhadap jumlah anakan, berat daun segar, berat daun kering, berat batang segar, berat batang kering dan bobot kering. Disamping itu waktu panen juga berpengaruh terhadap bobot rumput gajah cv Taiwan secara keseluruhan. Klon no 19, 1, 27,

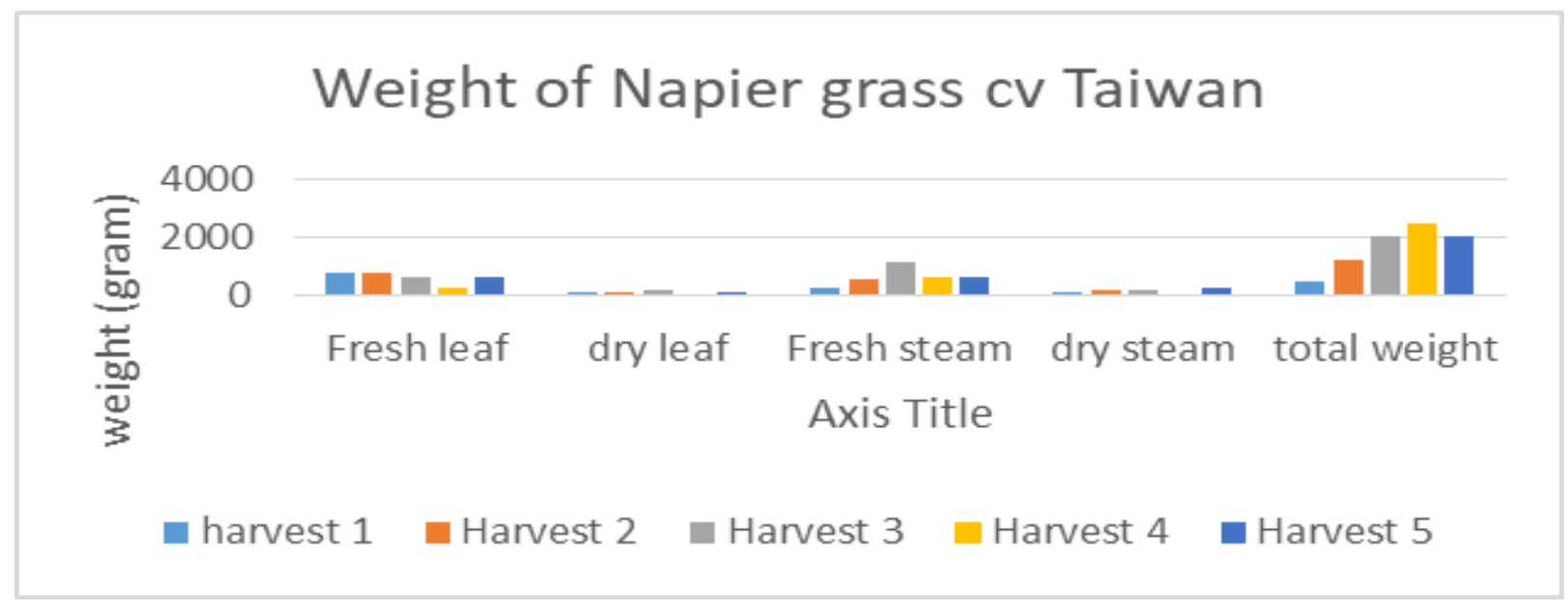

Gambar 1. Rata - rata hasil panen dari rumput gajah cv Taiwan 
31 dan 3 Untuk dikembang sebagai pakan ternak dengan persentase daun lebih besar dibanding batang.

\section{DAFTAR PUSTAKA}

Al Hafiizh, E., \& Ermayanti, T. M. (2014). Pengaruh iradiasi sinar gamma terhadap pertumbuhan tunas kultur in vitro Pennisetum purpureum. In E. Kaiin, B. Tappa, Y. Widyastuti, S. Said, \& P. Agung (Eds.), Bioresources untuk Pembangunan Ekonomi Hijaua (pp. 57-69). LIPI.

Astuti, N. P. (2007). Kandungan Reserpin Kultur Kalus Pule Pandak (Rauvolfia verticillata (Lour.) Baillon) Setelah Dielisitasi Dengan Cendawan Pytium sp [skripsi]. Universitas Sebelas Maret.

Budiman, B., Soetrisno, R. D., Budhi, S. P. S., \& Indrianto, A. (2012). Morphological characteristics, productivity and quality of three napier grass (Pennisetum purpureum Schum) cultivars harvested at different AGE. Journal of the Indonesian Tropical Animal Agriculture, 37(4), 294-301. https://doi.org/10.14710/ jitaa.37.4.294-301

Fanindi, A., Sutjahjo, S., Aisyah, S., \& Purwantari, N. D. (2016). Characteristic morphology and genetic variability of Benggala grass (Panicum maximum cv Purple guinea) through gamma ray irradiated on acid land. Jurnal Ilmu Ternak Dan Veteriner, 21(4), 205-214. https://doi.org/10.14334/jitv. v21i4.1635

Fanindi, A., Sutjahjo, S. H., Aisyah, S. I., \& Purwantari, N. D. (2019). Morphological characteristics and productivity of Guinea Grass (Panicum maximum CV Purple Guinea) irradiated with Gamma-Ray. Tropical Animal Science Journal, 42(2), 97-105. https://doi.org/10.5398/ tasj.2019.42.2.97

Gea, B., Karti, P., Prihantoro, I., \& Husni, A. (2019). Aklimatisasi dan Evaluasi Produksi Mutan Rumput Gajah Kultivar Taiwan. Jurnal Ilmu Nutrisi Dan Teknologi Pakan, 17(2), 47-53. https://doi.org/10.29244/jintp.17.2.47-53
Harmini, H., Sajimin, S., Fanindi, A., \& Husni, A. (2020). Keragaan Agronomi Rumput Gajah (Pennisetum purpureum cv Taiwan) Hasil Irradiasi Sinar Gamma. JINTP, 18(3), 62-66.

Haryani, H., Norlindawati, A. P., Norfadzrin, F., Aswanimiyuni, A., \& Azman, A. (2018). Yield and nutritive values of six napier (Pennisetum purpureum) cultivars at different cutting age. Malaysian Journal of Veterinary Research, 9(2), 6-12.

Lestari, R. H., Rusdy, M., Sema, S., \& Hasan, S. (2018). Effect of Liquid Organic Fertilizer and Defoliation Interval on Growth Characteristics and Quality of Elephant Grass CV.Taiwan. International Journal of Scientific and Research Publications (IJSRP), 8(10), 44-48. https://doi. org/10.29322/ijsrp.8.10.2018.p8208

Poehlman, J., \& Sleper, D. (1995). Breeding Field Crops. Panima Publishing Corporation.

Prihantoro, I., Anandia, A., Aryanto, A., Setiana, M., \& Karti, P. D. M. H. (2019). Tingkat adaptasi tanaman alfalfa (Medicago sativa L .) Hasil mutasi dengan sinar gamma pada skala lapang that irradiated with gamma rays on a field scale. Pastura, 9(1), 1-6.

Purba, K. R., Bayu, E. S., \& Nuriadi, I. (2013). Induksi mutasi radiasi sinar gammapada beberapa varietas kedelai hitam (Glycine $\max$ (L.) Merrill). Jurnal Online Agroekoteknologi, 3(2252), 58-66. http://www.tjyybjb.ac.cn/ $\mathrm{CN} /$ article / downloadArticleFile. do?attachType $=$ PDF\&id=9987

Reddy, B. V. S., Reddy, P. S., Bidinger, F., \& Blümmel, M. (2003). Crop management factors influencing yield and quality of crop residues. Field Crops Research, 84(1-2), 57-77. 